\title{
Business Wealth and Tax Policy
}

\author{
Robert M. Hull \\ School of Business, Washburn University, Topeka, KS, USA \\ Email: rob.hull@washburn.edu
}

How to cite this paper: Hull, R.M. (2019)

Business Wealth and Tax Policy. Theoretical Economics Letters, 9, 1020-1039.

https://doi.org/10.4236/tel.2019.94066

Received: March 6, 2019

Accepted: April 21, 2019

Published: April 24, 2019

Copyright $\odot 2019$ by author(s) and Scientific Research Publishing Inc. This work is licensed under the Creative Commons Attribution International License (CC BY 4.0).

http://creativecommons.org/licenses/by/4.0/

\begin{abstract}
This study has two major purposes. First, we extend capital structure model (CSM) research so that it can be applied to both ownership forms of forprofit organizations (FPOs): pass-throughs and C corp. We do this by deriving the first pass-through CSM equations. These equations complement the extant C corp CSM equations. Second, we derive new CSM equations to test tax policy reform. Since FPOs are responsible for most of federal tax revenue, these equations can produce outputs showing how FPO business wealth and federal tax revenue are changed when tax policy reform makes business growth more affordable by not taxing FPO earnings that are retained for growth. After deriving these new equations, we provide data in the form of effective tax rates and growth rates as well as a methodology to compute costs of borrowing. This data and methodology show how CSM equations can be applied to FPO studies. The major area of originality concerns the notion that both business wealth and federal tax revenue can increase if governments reform their tax policy by granting tax shields that promote growth while simultaneously doing away with tax shields that distorts owner efficiency caused by favoring debt over equity.
\end{abstract}

\section{Keywords}

Business Wealth, Tax Policy, Capital Structure Model

\section{Introduction}

The US Joint Committee on Taxation indicates that corporate income tax and individual income tax supply over 57\% of federal receipts for 2018 [1]. Those paying individual income tax (and thus following the personal income tax brackets) includes pass-through owners and workers employed by for-profit organizations (FPOs), nonprofits, and the government. FPOs supply about three quarters of the workforce and include the two major ownership forms: $\mathrm{C}$ corps and pass-throughs. In the US, pass-throughs consist of sole proprietorships, 
partnerships, limited liability companies, and $S$ corps. The pass-through label stems from the fact that taxable income "passes" through the business enterprise unscathed by taxes until it is received by individuals who are then taxed at the personal level. Pass-throughs and C corps are alike in that they come in all sizes with each consisting mostly of smaller businesses. Pass-throughs hire more workers than $\mathrm{C}$ corps and also produce well over twice the income of $\mathrm{C}$ corps. Despite their importance, pass-throughs receive less attention as most academic studies and textbook examples have large $\mathrm{C}$ corps in mind.

Without neglecting $\mathrm{C}$ corps, this study addresses the lack of pass-through attention by deriving new pass-through gain to leverage $\left(G_{L}\right)$ equations. In the process, we extend the Hull Capital Structure Model (CSM) that has focused on $G_{L}$ equations for C corps [2] [3] [4]. Extending the CSM to include passthroughs is important because we now have equations to study all FPOs. To illustrate the importance of evaluating all FPOs, this study derives new CSM equations based on a tax policy reform that makes business growth for all FPOs cheaper. Future research can use these equations to explore how business wealth and federal tax revenue can both increase when growth is not taxed. Future research can also examine how pass-through outputs compare with $\mathrm{C}$ corps outputs under the recent Tax Cuts and Job Acts (TCJA) that lowers tax rates.

By presenting equation for all FPOs, this paper is different from prior CSM papers since we are able to offer equations that analyze issues involving both FPO ownership forms. We show the value of such an analysis by formulating innovative FPO equations that significantly contribute to taxation research. Besides the tax policy reform mentioned above, these contributions can include efficiency in taxing, equality in the taxing of all ownership forms, and balancing of government budgets to prevent deficits. One area of originality offered in this paper's new CSM equations is the notion of replacing an interest tax shield with a partial retained earnings tax shield. This type of tax policy reform makes growth less expensive so that greater business wealth occurs opening the way for greater federal tax revenue.

The remainder of this paper is organized as follows. In Section 2, we examine pass-through features and capital structure models. Section 3 introduces the Capital Structure Model (CSM) and derives new and innovative CSM equations including for pass-throughs and tax policy reform. We address how the CSM's growth features guide this reform. Section 4 discusses CSM inputs. Section 5 provides examples of future research possibilities and offers conclusions.

\section{Pass-Through Features and Capital Structure Models}

\subsection{Pass-Through Features}

Until passage of TCJA in December 2017, a typical pass-through had a distinct after-tax valuation advantage compared to a typical $\mathrm{C}$ corp. This is because pass-throughs are free from corporate taxes. This pass-through tax advantage is reflected in the choice of ownership form. For example, the number of $\mathrm{C}$ corps 
have shrunk the past forty years while pass-throughs have tripled so that they outnumber $\mathrm{C}$ corps by about 18 to 1 [5]. This trend of businesses choosing the pass-through ownership form may be mitigated since TCJA favors $\mathrm{C}$ corps. For example, the maximum statutory federal tax rate for $\mathrm{C}$ corps $\left(T_{C}\right)$ fell from 0.35 to 0.21 while maximum personal tax rate for pass-throughs $\left(T_{E}\right)$ only dropped from 0.396 to 0.37 , albeit some pass-throughs receive other benefits such as a deduction equal to $20 \%$ of the pass-through's business income.

The relation between debt and equity for pass-throughs can be murky especially when trying to distinguish between partnership debt and partnership equity [6]. In terms of equity, pass-throughs target a smaller number of investors (partners or venture capitalists) for their funding. In contrast, large $\mathrm{C}$ corps have public equity offerings that can involve thousands of individuals and institutional investors. As a result, pass-throughs are less likely to experience negative signaling that accompanies a public offering where owners are suspected of issuing overvalued equity securities.

While small pass-throughs achieve debt financing by using a credit card or trade credit, larger pass-throughs take on debt by issuing notes, bonds, and other obligations. Pass-through debt financing often includes regional and national mezzanine borrowings that permit the issuance of unsecured and subordinated notes at high interest rates [7]. Pass-throughs can also borrow from individuals, banks, savings and loans, credit unions, commercial finance companies, and SBA guaranteed loans. SBA loans have methods of motivating bank and non-bank lenders to make long-term loans to pass-throughs.

While pass-throughs are typically smaller in size compared to C corps, both cover all firm sizes. Regardless of size, both should generally be subject to the same market and credit conditions so that there are classes of pass-throughs and $\mathrm{C}$ corps that can be compared. Thus, tests can be conducted based on different market scenarios and credit risk classes for which both pass-throughs and $\mathrm{C}$ corps have the same market risk scenario and credit class. Such comparisons can isolate the difference in taxes so that conclusions can be made concerning the impact of the ownership form based on differences in tax rates.

\subsection{Capital Structure Models}

Even though corporate governance research is often geared towards C corps, it is adaptable to pass-throughs as all ownership forms share in the common goal of profit-maximization. In addition, despite tax rates differences, FPO ownership forms exercise similar business practices (performance-based wages, optimal financing, working capital management, payout policy) needed to insure the goal of profit maximization. Thus, much of mainline capital structure theory should be applicable not only to $\mathrm{C}$ corps but also pass-throughs.

Researchers indicate that capital structure theory is inexact, provides ambiguous guidance, and explains only part of the observed behavior regarding leverage choices [8] [9] [10]. The heart of this indictment suggests that searching for 
an adequate capital structure model for FPOs presents difficulties. In our opinion, an adequate model should exhibit the following characteristics: compact yet inclusive, derived from definitions, and precise and believable. Compact yet inclusive refers to a succinct model that only contains the most relevant inputs. Derived from definitions means that a model and its inputs are well-defined. This implies that the inputs would be measurable with enough accuracy to produce reliable outputs. Preciseness and believable refers to the serviceability of the model's outputs in terms of precise dollar amounts or percentages that are believable in being consistent with empirical research and real world data.

A starting point for determining an adequate capital structure model is the model by Modigliani and Miller, referred to as MM [11]. The MM model offers a corporate tax-based perpetuity $G_{L}$ equation that focuses on the debt tax shield. A strength of the MM model is that it is compact by only using two variables as the debt tax shield is simply the corporate tax rate times the debt issued. However, a weakness exists as it is not inclusive since it ignores growth and financial distress costs that increase with debt. Since $G_{L}$ is by definition firm value $\left(V_{L}\right)$ minus unlevered firm value $\left(V_{U}\right)$ and these definitions include costs of borrowing, the MM model fails the derived from definitions test because its $G_{L}$ equations excludes a full complement of costs of borrowing. While the MM model can compute $G_{L}$ for any given amount of debt, the MM model fails the believability test as it implies that large, and even unrestricted amounts of debt, can be issued.

The major extension of MM is the Miller Model [12]. The Miller model includes a role for personal taxes in capital structure choice and builds on prior research [13]. While more inclusive than MM by allowing for personal tax rates, there is still an inclusive concern as the Miller $G_{L}$ equation, like the MM $G_{L}$ equation, does not directly account for growth or financial distress effects that rise with more leverage. The Miller model shares the same MM problem in terms of the derived by definition criterion by not explicitly containing all costs of borrowing. While capable of giving preciseness in a dollar $G_{L}$ output, the Miller model often has trouble passing the believability test as the Miller model suggests that a typical firm can issue either zero debt or unlimited amounts of debt. Both of these outcomes do not reflect observed managerial behavior where managers pursue reasonable debt levels based on targeting bond ratings [14].

In contrast to the MM-Miller models, agency models [15] [16] [17] [18] and pecking order models [19] [20] [21] provide less direction on how to compute exact $G_{L}$ values as these models are not known for compact $G_{L}$ equations with measurable inputs. For example, how does one quantify the myriad of agency costs and benefits? While pecking order models exhibit a strength in being straightforward in terms of the order of financing preferences, they also produce concerns about how to measure costs. For example, how do we accurately measure asymmetric information costs? In addition, agency and pecking order models are not derived from definitions as their main purpose is not to supply an exact computation of the maximum firm value but to explain why one form of 
financing would be preferred over another. In brief, while agency and pecking order models provide insight on managerial financing behavior and practices, they are lacking formulations that contains measurable inputs capable of pinpointing preciseness in debt choice, valuation and leverage gain outputs. These outputs are needed for proper capital structure decision-making.

Trade-off models [22] [23] [24] advocate the existence of an optimal debt-tofirm value $(O D V)$. This area of research is abundant and offers insight on how firm value can be increased by the correct financing choices. These models are sophisticated and exhibit many strengths and so can reasonably satisfy the characteristics we mentioned. However, they generally prove impractical in terms of application by a practitioner be it an FPO manager or government policy maker. For the purposes of this paper, we desire something more user-friendly and the CSM satisfies this desire. It is also consistent with trade-off models (as it contains multi-components that are equipped to handle both positive and negative leverage effects). The CSM also produces believable outcomes as its results [7] [25] are consistent with the empirical research [26] [27] [28] that finds unlevered equity can increase $4 \%$ to $10 \%$ by being at $O D V$.

\section{CSM Equations}

This section extends C corp CSM equations by not only deriving pass-through CSM equations but also four new and innovative CSM equations for a tax policy reform that makes growth less expensive for FPOs. While CSM equations can have the same expression for the first two components, each equation is unique because variables in the components are defined based on differences in tax laws that govern ownership tax rates and on dissimilarities in tax policies that govern the deductibility of expense items. We denote differences in the CSM $G_{L}$ equations by the subscripts attached to the left-hand side of each equation.

\subsection{CSM C Corp and Pass-Through Equations with ITS}

Using the definition that the $G_{L}$ is levered firm value $\left(V_{L}\right)$ minus unlevered firm value $\left(V_{U}\right)$ where $V_{U}$ is also referred to as unlevered equity $\left(E_{U}\right)$, Hull [2] derives $G_{L}$ for a nongrowth C corp. Hull [3] updates this $G_{L}$ equation to incorporate changes in tax rates and shows

$$
G_{L_{C \text { Corp-ITS }}^{D \rightarrow E}}^{D(\text { Nongrowth })}=\left[1-\frac{\alpha_{1} r_{D}}{r_{L}}\right] D-\left[1-\frac{\alpha_{2} r_{U}}{r_{L}}\right] E_{U}
$$

where $D \rightarrow E$ indicates a debt-for-equity transaction and ITS refers to the annual perpetuity interest tax shield that occurs under tax laws for most developed countries that allow interest $(I)$ as a deductible expense where $I T S=T_{C 2}(I)$ with $T_{C 2}$ as the levered effective tax rate on corporate income;

$\alpha_{1}=\left(1-T_{E 2}\right)\left(1-T_{C 2}\right) /\left(1-T_{D}\right)$ with $T_{E 2}$ and $T_{D}$ as the levered effective tax rates on equity and debt incomes, respectively; $r_{D}, r_{U}$ and $r_{L}$ are the costs of debt, unlevered equity, and levered equity, respectively; $\operatorname{debt}(D)=\left(1-T_{D}\right) I / r_{D}$; $\alpha_{2}=\left(1-T_{E 2}\right)\left(1-T_{C 2}\right) /\left(1-T_{E 1}\right)\left(1-T_{C 1}\right)$ with $T_{E 1}$ and $T_{C 1}$ as the unlevered effec- 
tive tax rates on equity and corporate incomes; $E_{U}\left(\right.$ or $\left.V_{U}\right)=\left(1-T_{E 1}\right)\left(1-T_{C 1}\right) C / r_{U}$ with $C=(1-P B R) C F_{B T}$ where $C$ is the equity cash payout and $P B R$ is the before-tax plowback ratio that equals 0 since (1) assumes nongrowth and $C F_{B T}$ is the perpetual before-tax cash flow; and, levered equity $\left(E_{L}\right)=$ $\left(1-T_{E 2}\right)\left(1-T_{C 2}\right)(C-I) / r_{L}$.

Hull [29] incorporates growth through internal equity or retained earnings $(R E)$ and derives $G_{L}$ for a growth C corp. Hull [3] updates this $G_{L}$ equation to incorporate changes in tax rates and shows

$$
G_{L_{C \text { Corp }-I T S}^{D \rightarrow E}}(\text { Growth })=\left[1-\frac{\alpha_{1} r_{D}}{r_{L g}}\right] D-\left[1-\frac{\alpha_{2} r_{U g}}{r_{L g}}\right] E_{U}
$$

where $r_{U g}$ and $r_{L g}$ are the growth-adjusted costs of borrowing on unlevered and levered equity with $r_{U g}=r_{U}-g_{U}$ and $r_{L g}=r_{L}-g_{L}$ where $g_{U}$ and $g_{L}$ are the growth rates for unlevered and levered equity. While $g_{U}$ depends on the plowback-payout decision, $g_{L}$ depends on both the plowback-payout and debt-equity decisions. For growth, we now have $E_{U}$ (or $\left.V_{U}\right)=\left(1-T_{E 1}\right)\left(1-T_{C 1}\right) C / r_{U g}$ and $E_{L}=\left(1-T_{E 2}\right)\left(1-T_{C 2}\right)(C-I) / r_{L g}$. Because $P B R>0$ now holds, $C F_{B T}=C+R E$ whereas with nongrowth $C F_{B T}=C$. For growth, debt is unchanged and so $D=\left(1-T_{D}\right) I / r_{D}$ and the debt tax shield remains $I T S=T_{C 2}(I)$. While growth results from $R E$, there is no $R E \operatorname{tax}$ shield ( $R T S$ ) for now and so $R T S=0$.

When formulating (2), Hull [29] derives an unlevered growth rate $\left(g_{U}\right)$ for a C corp. This rate is $g_{U}=r_{U}\left(1-T_{C 1}\right) R E / C$. Hull shows that growth is only profitable for a $C$ corp using $R E$ if $P B R>T_{C 2}$ holds where $T_{C 2}$ is the cost of using $R E$ since taxes are paid before it can be used. Additionally, Hull develops a levered growth rate $\left(g_{L}\right)$ for a C corp. As corrected by Hull [4], this growth rate is $g_{L}=r_{L}\left(1-T_{C 2}\right) R E /\left[C+G-\left(1-T_{C 2}\right) I\right]$ where $G$ is the perpetual before-tax cash flow from $G_{L}$ with $G=r_{L g}\left(G_{L}\right) /\left(1-T_{E 2}\right)\left(1-T_{C 2}\right)$. Besides correcting $g_{L}$, Hull develops constraints for $\mathrm{C}$ corps when using (1) and (2). The C corp $R E$ (or growth) constraint when using (2) is $C+G-\left(1-T_{C 2}\right) I \geq R E$. If there is no growth (e.g., $R E=0$ ), this $R E$ constraint implies the $\mathrm{C}$ corp nongrowth constraint of $C+G \geq\left(1-T_{C 2}\right) I$, which is used with (1).

As just seen, a key feature of the CSM is its emphasis on the cost of growth. This feature has implications for tax policy. For example, consider the marginal effective tax rate, defined as the rate that satisfies a businesses investment after taxes are considered. Tax experts suggests that this marginal rate is too high for businesses and thus prevents growth. While the U.S. has one of the highest marginal effective tax rates, the problem is systemic throughout the world. One way to solve this problem is to change tax policy in a manner where growth is less expensive. An implication of the CSM is that this can be done by lowering taxes on RE. Later, in Section 3.2, we will address this implication.

In Appendix A, we derive the $G_{L}$ equation for a pass-through with nongrowth. This equation is

$$
G_{L_{P T-I T S}}^{D \rightarrow E}(\text { Nongrowth })=\left[1-\frac{\alpha_{1} r_{D}}{r_{L}}\right] D-\left[1-\frac{\alpha_{2} r_{U}}{r_{L}}\right] E_{U}
$$


where $P T$ denotes a pass-through and $I T S=T_{E 2}(I)$. While (3) has the same expression as (1) in terms of its first two components, Appendix A shows that the C corp multiplicands with the corporate tax rate fall out of the definitions for $\alpha_{1}$, $\alpha_{2}, G, E_{U}$, and, $E_{L}$. This is because pass-throughs are not taxed at the corporate level.

Hull and Price [7] apply a nongrowth CSM to a pass-through but without changes in tax rates. For an application without changes in tax rates, a nongrowth pass-through equation is, practically speaking, the same as a $\mathrm{C}$ corp equation with no growth and no changes in tax rates. Thus, because Hull and Price do not allow tax rates to change, they had no need to derive and use the nongrowth pass-through CSM equation that we offer in Appendix A.

In Appendix B, we derive the $G_{L}$ equation for a pass-through with growth. This equation is

$$
G_{L_{P T-I T S}^{D \rightarrow E}}(\text { Growth })=\left[1-\frac{\alpha_{1} r_{D}}{r_{L g}}\right] D-\left[1-\frac{\alpha_{2} r_{U g}}{r_{L g}}\right] E_{U} .
$$

While (4) expresses its two components like (2), Appendix B shows that the C corp definitions have been altered in a fashion like that found in Appendix A to account for pass-through tax law. In addition, since (4) uses growth, the C corp definitions for $g_{U}$ and $g_{L}$ are also altered by replacing the corporate tax rate with the pass-through personal tax rate. This is because $R E$ is taxed at the personal pass-through level and $I$ gives a tax shield at the personal pass-through tax level. Thus, we now have

$$
g_{U}=r_{U}\left(1-T_{E 1}\right) R E / C \text { and } g_{L}=r_{L}\left(1-T_{E 2}\right) R E /\left[C+G-\left(1-T_{E 2}\right) I\right]
$$

where $G=r_{L g}\left(G_{L}\right) /\left(1-T_{E 2}\right)$. Similarly, the constraints for pass-throughs replace the corporate tax rate with the personal pass-through tax rate. Thus, for pass-throughs, the $R E$ constraint used with (4) is $C+G-\left(1-T_{E 2}\right) I \geq R E$ and the nongrowth constraint used with (3) is $C+G \geq\left(1-T_{E 2}\right) I$.

\subsection{CSM C Corp and Pass-Through Equations with RTS}

An efficient tax policy should allow for growth without government barriers. Such a barrier exists when $R E$ is significantly taxed. This barrier can be overcome by having an $R E$ tax shield ( $R T S$ ). The next four CSM equations reduce (in varying degrees) the taxes paid on $R E$ where the CSM defines $R E$ as the cash flows used directly for growth. To offset the lost federal tax revenue from not taxing $R E$, we allow $I$ to be taxed. Eliminating the tax shield on $I$ simultaneously solves the problem that a debt tax shield distorts owner efficiency because it favors debt over equity. Thus, we change tax policy by replacing ITS with RTS in Equations (5) and (6). For Equations (7) and (8), we consider a partial ITS and/or a partial RTS.

Appendix $\mathrm{C}$ derives a $\mathrm{C}$ corp growth CSM equation when we replace ITS with $R T S$. This equation is 


$$
G_{L_{C \text { Corp }-R T S}^{D \rightarrow E}}(\text { Growth })=\left[1-\frac{\alpha_{1} r_{D}}{r_{L g}}\right] D-\left[1-\frac{\alpha_{2} r_{U g}}{r_{L g}}\right] E_{U}
$$

where $R T S$ refers to the annual perpetuity $\mathrm{C}$ corp $R E$ tax shield with $R T S=$ $T_{C 2}(R E)$ and $I T S$ now equals zero as $I$ is no longer shielded from corporate taxes. As described in Appendix C, we modify the C corp definitions for $\alpha_{1}, D, g_{U}$ and $g_{L}$ given when presenting (2). The modifications are based on tax policy reform that changes which expenses are tax deductible.

Appendix D derives a pass-through growth CSM equation when we replace $I T S$ with $R T S$. This equation is

$$
G_{L_{P T-R T S} \rightarrow E}^{D \rightarrow}(\text { Growth })=\left[1-\frac{\alpha_{1} r_{D}}{r_{L g}}\right] D-\left[1-\frac{\alpha_{2} r_{U g}}{r_{L g}}\right] E_{U}
$$

where $R T S$ refers to the annual perpetuity pass-through $R E$ tax shield with $R T S$ $=T_{E 2}(R E)$ and $I T S$ now equals zero as $I$ is no longer shielded from taxes at the pass-through level. As described in Appendix D, we alter the pass-through definitions for $\alpha_{1}, D, g_{U}$, and $g_{L}$ given when presenting (4) based on changes in the deductible expenses.

The use of Equations (5) and (6) reveal what will happen to business wealth and federal tax revenue if we do not shield $I$ from taxes while providing a tax shield on $R E$. By doing this, the cost of using internal funds retained for growth is less expensive and the cost of debt is more expensive. The lost federal tax revenue from not taxing $R E$ would be offset by the gain in federal tax revenue from taxing $I$ and also the gain in federal revenue associated with greater business growth when $R E$ is not taxed.

Appendix E presents a C corp growth $G_{L}$ equation for a partial $I T S$ and/or a partial $R T S$. Not only is there a tax policy change in allowing an RTS but the tax rate on $I$ and/or $R E$ is, in essence, altered. As described in Appendix E, this equation is a hybrid of (2) and (5) with the same expression but different definitions. Appendix E shows that

$$
G_{L_{C} \text { Corp-Partial }}^{D \rightarrow E}(\text { Growth })=\left[1-\frac{\alpha_{1} r_{D}}{r_{L g}}\right] D-\left[1-\frac{\alpha_{2} r_{U g}}{r_{L g}}\right] E_{U}
$$

where partial refers to the use of partial tax shields that are achieved by changing factor values. As described in Appendix E, these factors enable the FPO to achieve ITS and RTS values ranging from a zero tax shield to a full tax shield where full means there is a $100 \%$ tax shield on the applicable variable be it $I$ or $R E$.

Appendix F presents a pass-through growth $G_{L}$ equation for a partial ITS and/or a partial $R T S$. This equation is

$$
G_{L_{P T-P a r t i a l}}^{D \rightarrow E}(\text { Growth })=\left[1-\frac{\alpha_{1} r_{D}}{r_{L g}}\right] D-\left[1-\frac{\alpha_{2} r_{U g}}{r_{L g}}\right] E_{U} .
$$

As described in Appendix F, this equation is a hybrid of (4) and (6) with the same expression but different definitions. Equations (7) and (8) can be used with 
a tax policy that allows individual FPOs to choose what type of tax shield they prefer or to even select both a partial ITS and a partial RTS.

When using (7) and (8), we propose mandating a limit on how much $I$ and/or $R E$ should be used as a tax deduction. Within this limit, it should be left up to the FPO's discretion to allocate their tax deduction to maximize their business wealth. A tax policy with an option for each FPO to allocate between $R E$ and $I$ should prevent potential problems. For example, it should prevent an FPO from choosing growth just to get a retained earnings tax deduction when growth is not desirable. Similarly, it would inhibit FPOs from issuing too much debt just to get an interest tax deduction. If the real purpose of debt is to raise funds for growth in the least expensive manner, then having the option of an $R E$ tax deduction should provide an even cheaper means of growth. The key is for policy makers is to choose a limit on tax deductions that does not allow for an unhealthy wealth transfer between FPOs and federal coffers by permitting too little or too much of a tax shield. Proper testing using Equations (7) and (8) should help provide the optimal limit governing any tax shield so that business wealth increases and the government has enough tax revenue to cover its responsibilities.

\section{CSM Inputs: Tax Rates, Costs of Borrowing, and Growth Rates}

This section discusses CSM inputs that consist of tax rates, borrowing costs, and growth rates. We provide reasonable values for tax rates and growth rates and a method for getting borrowing costs used as discount rates when applying the CSM equations.

\subsection{Tax Rates}

Prior to TCJA, the Tax Policy Center [30] notes that over two-thirds of passthroughs are taxed at either the maximum rate of 0.396 or the 0.28 alternative minimum tax rate suggesting an effective (or average) tax rate of around 0.34 if we use a middle point of that range. Tax researcher indicate that most passthroughs experience a personal equity tax rate below 0.3 [31] [32] [33]. Taking into account all sources and the recent fall in $T_{E}$ due to TCJA, an effective $T_{E}$ around 0.31 might be considered a reasonable estimate albeit the median would be lower. Because we begin with an unlevered firm and allow tax rates to change when debt increases as described by Hull [3], tests could start with an unlevered tax rate of 0.37 if we want a $T_{E}$ near 0.31 at $O D V$ (where $O D V$ is around 0.35 if we use the midpoint of the $O D V$ range of 0.3 to 0.4 given in Section 4.2). A $T_{E}$ value of 0.31 at $O D V$ (or any debt level greater than zero) is referred to as a levered $T_{E}$.

Given that the maximum corporate tax rate $\left(T_{C}\right)$ of 0.21 is well below the maximum $T_{E}$ of 0.37 , an effective $T_{C}$ of 0.15 for $\mathrm{C}$ corps is a value commensurate with the effective $T_{E}$ of 0.31 for pass-throughs. Considering that $T_{C}$ is a flat rate under TCJA and tax credits and tax deductions may be more difficult to attain under TCJA, an effective $T_{C}$ of 0.15 is too low. Thus, an effective $T_{C}$ of 0.175 is 
more reasonable at $O D V$ and could be used with an unlevered $T_{C}$ of 0.21 .

Like $\mathrm{C}$ corp debt owners, interest distributions for pass-through debt owners are taxed at the personal debt tax rate $\left(T_{D}\right)$. If debt is held longer than three years, any capital gains is taxed at a lower capital gains rate with a typical maximum $T_{D}$ of 0.20 for which we expect a lower effective $T_{D}$ of 0.15 . Because we expect most debt to be held three years, an effective $T_{D}$ of 0.15 is more likely than a higher rate based on the maximum $T_{D}$ of 0.37 . However, an estimate of 0.15 is low if one computes an effective $T_{D}$ based on the imputed $T_{D}$ from municipal bond and corporate Aaa bond yields. Such a computation indicates an effective rate around 0.18 using current yields and the bond rating data from Damodaran [34]. Given the above estimates of 0.15 and 0.18 , a reasonable effective $T_{D}$ is 0.165 for a typical pass-through at $O D V$. To achieve a $T_{D}$ value near 0.165 at $O D V$ an unlevered $T_{D}$ value near 0.14 would be assigned. Unlike $T_{C}$ and $T_{E}$ that fall with leverage, $T_{D}$ rises with leverage.

Unlike pass-throughs, $C$ corps have many investors who buy and sell public shares and receive dividends and capital gains. These investors are subject to tax laws similar to debt owners but with a greater capacity for deferral of taxes. For this reason, we advocate a personal tax rate on dividends and capital gains of about 0.09 as the $\mathrm{C}$ corp effective $T_{E}$. To achieve a $T_{E}$ near 0.09 at $O D V$, the unlevered $T_{E}$ would be about 0.11 .

\subsection{Costs of Borrowing}

In terms of a procedure to get the costs of borrowing that correspond to $P\left(E_{U}\right)$ choices where $P\left(E_{U}\right)$ is the proportion of unlevered equity retired with debt, researchers argue for the use of credit ratings as they rank higher than traditional factors in determining capital structure decision-making [8] [35]. One can gather credit spreads of 30-year corporate bonds over 30-year treasury bond from Damodaran [34] who supplies spreads for fifteen bond ratings. Spreads can be added to a long-term risk-free rate $\left(r_{F}\right)$ to get costs of borrowings. An $r_{F}$ of $3 \%$ is consistent with the long-term government bonds from U.S. Municipal Bonds [36]. It is also characteristic of rates for the past eight years. To get the costs of equity to match each cost of debt, one can add an equity risk premium $(E R P)$ to each cost of debt. We estimate ERP to be in the neighborhood of $4.75 \%$ based on sources including Damodaran. Costs of borrowing can be adjusted up or down if one is testing a riskier or less risky scenario.

In terms of estimating costs of borrowing for pass-throughs, a problem emerges when using credit ratings. This is because, compared to $\mathrm{C}$ corps, pass-through debt is less likely to be subject to a public credit rating. While it may be difficult to compare one individual $\mathrm{C}$ corp with an individual pass-through, a general study of ownership form has to only acknowledge there is a risk class of pass-throughs that would fit the public credit rating attached to a risk class of $\mathrm{C}$ corps. On a macro level, one can assume similar risk since $\mathrm{C}$ corps and pass-throughs both are dominated by businesses with a small size. 
When matching the credit ratings with $P\left(E_{U}\right)$ choices, one can consult various sources [37] [38] that give the relation between credit ratings and leverage ratios. There is evidence that $O D V s$ for all FPOs can be similar so that pass-throughs and $\mathrm{C}$ corps may not deviate much in terms of a typical $O D V$. For example, Bowman [39] suggests that long-term debt for pass-throughs averages 0.25 of their capital assets. Given Bowman's omission of short-term debt, an average pass-through $O D V$ could be estimated to be from 0.3 to 0.4. Damodaran [34] reports an average near 0.3 for a ratio composed of market debt to capital asset. Hull, Kwak, and Walker [40] analyze a sample of smaller 1189 seasoned equity offerings from 1999-2010 and find a similar value. While there can be great variation in what individual FPOs consider as their optimal target credit rating, it is likely that a typical FPO will achieve its $O D V$ at a $\mathrm{BBB}$ rating that (for the most recent credit ratings) corresponds to an $O D V$ that could approach 0.4 . Thus, we suspect an $O D V$ range for $\mathrm{C}$ corps of 0.3 to 0.4 that is similar to pass-throughs. While we estimate a range from 0.3 to 0.4 for a typical FPO, a study of an individual sample of FPOs will take on a wide range of target debt levels. To illustrate, Graham and Harvey [8] survey 392 CFOs about their debt usage as measured in book values terms by debt-to-total assets. They find that one-third is below 0.2 , one-third is between 0.2 and 0.4 , and the remaining is greater than 0.4 .

\subsection{Setting Growth Rates}

In addition to tax and borrowing rates, long-run growth rates need to be determined. Since we want a proxy for growth in business wealth, we recommend using growth rates based on real growth in GDP over thirty to seventy year periods such as supplied by the US. Bureau of Economic Analysis [41]. Since TCJA lowers tax rates and empirical research finds that lower tax rates increases growth, we propose using a higher growth for TCJA tests compared to pre-TCJA tests. The Joint Committee on Taxation (JCT) of the US Congress [1] recommends a growth rate that is about $0.8 \%$ higher with lower tax rates. Based on estimates from long-run growth rates in real US GDP, we suggest a growth rates of $3.12 \%$ for pre-TCJA tests and $3.90 \%$ for TCJA tests. If this adjustment is not made when comparing pre-TCJA and TCJA results, findings will be subject to error as TCJA results for business wealth and federal tax revenue will be underestimated.

If we restrict $g_{L}$ to historical sustainable rates such as $3.12 \%$ and $3.90 \%$, we have to undergo a two-step procedure to try to determine the optimal $P\left(E_{U}\right)$ choice. First, we run tests using the CSM for all feasible $P\left(E_{U}\right)$ choices excluding choices where the $R E$ constraint sets in. Since $R E=P B R\left(C F_{B T}\right)$ and the CSM $g_{L}$ was defined earlier in terms of $R E$, we are able to change $P B R$ until our chosen $g_{L}$ is achieved for each $P\left(E_{U}\right)$ choice. Second, we identify the $P\left(E_{U}\right)$ choice that generates the maximum $V_{L}$ among all possible $P\left(E_{U}\right)$ choices and this $P\left(E_{U}\right)$ choice is the optimal. However, there are caveats that must be faced with this two-step procedure. For instance, this procedure assumes that our chosen historical growth rate can be attained for all feasible $P\left(E_{U}\right)$ choices. This means we would 
have to assume that the highest possible investment grade bond could sustain a historical growth rate when we know this is not likely because the levered equity growth is an increasing function of debt making it difficult for a typical FPO to achieve a large sustainable $g_{L}$ at a low debt level. Furthermore, if we set our chosen $g_{L}$ to a lower debt level that corresponds to a very high investment grade rating, we could not get $O D V$ values between 0.3 and 0.4 , which are values that typically occur.

Given problems that can surface in our two-step procedure, we look at the optimal $P\left(E_{U}\right)$ choice for the nongrowth test as this test yields one and only one $P\left(E_{U}\right)$ value that maximizes firm value. Of importance, we have discovered that nongrowth tests give a $P\left(E_{U}\right)$ choice and $O D V$ consistent with both our two-step procedure and also researchers such as Damodaran [34]. For tests using macro data that capture a typical FPO, we suspect tests will generate an optimal $P\left(E_{U}\right)$ choice that is determined by the large jump from an investment grade bond to a speculative bond that is found in most recent spreads. Suppose we have overestimated the optimal debt level choice as researchers often point out that firms are underlevered. In testing this notion, we find that a lower debt choice does not appear to affect results as maximum $V_{L}$ often changes very little.

\section{Future Research and Conclusions}

An important contribution of this paper's CSM extension is that the CSM can now be applied to both major FPO ownership forms. This widens the potential for financial innovations when conducting future research. While the possibilities for innovation are many, this study has focused on tax policy reform and the two below possibilities.

First, by having both pass-through and C corp CSM equations, we can compute business wealth for all FPOs before and after TCJA. Thus, we can perform a study measuring the effect of TCJA on federal tax revenue. This study is possible because federal tax revenue should change in the direction of business wealth. Additionally, federal revenue paid by FPOs and all individual filers (who work for FPOs) has a significant impact on the federal budget because it produces most of the federal receipts. When conducting pre-TCJA and TCJA tests, it is crucial to change the growth rate as the lowering of taxes leads to greater growth. Thus, TCJA tests would use a higher tax rate where experts propose that the growth rate would be about $0.8 \%$ greater with lower tax rates.

Second, keeping with the tax theme, consider innovations in tax policy related to accounting items such as retained earnings $(R E)$ and interest paid $(I)$. The CSM has the capacity to show how lowering the expense on $R E$ increases business wealth through greater growth. Lost tax revenue from not taxing $R E$ can be offset by doing away with the tax shield on $I$. The CSM equations given in (7) and (8) cover the allowance of a partial tax shield on $I$ and/or $R E$ and are best equipped to show precisely how lowering tax on growth (e.g., $R E$ ) can increase business wealth and thus federal tax revenue. While the purpose of this paper is to present new equations and not results, tentative findings suggest these two 
equations can guide tax policy reform in maximizing business wealth, achieving greater federal tax revenue, and realizing greater fairness in taxing of FPO ownership forms.

The limitations of this research are as follows. First, we use a perpetuity valuation model. This model relies on estimates for inputs that are based on historical numbers and current expectations. Values for these estimate can change over time creating findings that are time dependent. Second, whereas we have offered data for tax rates and growth rates as well as a methodology for computing costs of borrowing, there can be reasonable disagreements on the actual data and methodology used to get values.

In conclusion, this paper has produced new equations that enable practitioners to discover financial innovations through computing debt choice, valuation, and leverage gain outputs for the two major ownership types with these outputs able to address major issues such as tax policy reform. Of importance, the innovative equations offered in this paper include the neglected area of pass-throughs. Proper application of these equations can lead to accurate results when studying important topics such as tax policy reform with the reasons for the accuracy being that borrowing costs are tied to bond rating spreads and long-run growth rates are derived from historical sustainable average growth rates. Finally, proper application of this paper's equations can offer insight to help managers know if growth is valuable and to what extent it is valuable for diverse market risk scenarios, different industries, and dissimilar tax rate schemes.

\section{Conflicts of Interest}

The author declares no conflicts of interest regarding the publication of this paper.

\section{References}

[1] The Joint Committee on Taxation (2018) Overview of the Federal Tax System as in Effect for 2018 (JCX-3-18), 7 February 2018. https://www.jct.gov/publications.html?func=startdown\&id $=5060$

[2] Hull, R. (2007) A Capital Structure Model. Investment Management and Financial Innovation, 4, 8-24.

[3] Hull, R. (2014) A Capital Structure Model (CSM) with Tax Rate Changes. Investment Management and Financial Innovations, 11, 8-21.

[4] Hull, R. (2018) Capital Structure Model (CSM): Correction, Constraints, and Applications. Investment Management and Financial Innovation, 15, 245-262. https://doi.org/10.21511/imfi.15(1).2018.21

[5] Hodge, S. (2014) The U.S. Has More Individually Owned Businesses than Corporations. https://taxfoundation.org/us-has-more-individually-owned-businesses-corporations

[6] Dantzler, J.W. (2017) The Distinction between Partnership Debt and Partnership Equity.

https://www.whitecase.com/publications/article/distinction-between-partnership-de bt-and-partnership-equity 
[7] Hull, R. and Price, D. (2015) Pass-Through Valuation. The Journal of Entrepreneurial Finance, 17, 82-116.

[8] Graham, J. and Harvey, C. (2001) The Theory and Practice of Corporate Finance: Evidence from the Field. Journal of Financial Economics, 60, 187-243. https://doi.org/10.1016/S0304-405X(01)00044-7

[9] Graham, J. and Leary, M. (2011) A Review of Empirical Capital Structure Research and Directions for the Future. Annual Review of Financial Economics, 3, 309-345. https://doi.org/10.1146/annurev-financial-102710-144821

[10] Leland, H. (1998) Agency Costs, Risk Management, and Capital Structure. Journal of Finance, 53, 1213-1243. https://doi.org/10.1111/0022-1082.00051

[11] Modigliani, R. and Miller, M. (1963) Corporate Income Taxes and the Cost of Capital: A Correction. American Economic Review, 53, 433-443.

[12] Miller, M. (1977) Debt and Taxes. Journal of Finance, 32, 261-275.

[13] Farrar, D. and Selwyn, L. (1967) Taxes, Corporate Financial Policy, and Returns to Investors. National Tax Journal, 20, 444-454.

[14] Kisgen, D. (2009) Do Firms Target Credit Ratings or Leverage Levels? Journal of Financial and Quantitative Analysis, 44, 1323-1344. https://doi.org/10.1017/S002210900999041X

[15] D’Melloa, R. and Miranda, M. (2010) Long-Term Debt and Overinvestment Agency Problem. Journal of Banking and Finance, 34, 324-335. https://doi.org/10.1016/j.jbankfin.2009.07.021

[16] Gay, G. and Nam, J. (1998) The Underinvestment Problem and Corporate Derivatives Use. Financial Management, 27, 53-69.

[17] Jensen, M. and Meckling, W. (1976) Theory of the Firm: Managerial Behavior, Agency Costs and Ownership Structure. Journal of Financial Economics, 3, 305-360. https://doi.org/10.1016/0304-405X(76)90026-X

[18] Jensen, M. (1986) Agency Costs of Free Cash Flow, Corporate Finance, and Takeovers. American Economic Review, 76, 323-329.

[19] Donaldson, G. (1961) Corporate Debt Capacity: A Study of Corporate Debt Policy and the Determination of Corporate Debt Capacity. Harvard Business School, Boston.

[20] Myers, S. (1977) Determinants of Corporate Borrowing. Journal of Financial Economics, 5, 147-175. https://doi.org/10.1016/0304-405X(77)90015-0

[21] Myers, S. and Majluf, N. (1984) Corporate Financing and Investment Decisions when Firms Have Information that Investors Do Not Have. Journal of Financial Economics, 13, 187-221. https://doi.org/10.1016/0304-405X(84)90023-0

[22] Baxter, N. (1967) Leverage Risk of Ruin and the Cost of Capital. Journal of Finance, 22, 395-403.

[23] Berk, J., Stanton, R. and Zechner, J. (2010) Human Capital, Bankruptcy and Capital Structure. Journal of Finance, 65, 891-926. https://doi.org/10.1111/j.1540-6261.2010.01556.x

[24] De Angelo, H. and Masulis, R. (1980) Optimal Capital Structure under Corporate and Personal Taxation. Journal of Financial Economics, 8, 3-29. https://doi.org/10.1016/0304-405X(80)90019-7

[25] Hull, R. (2011) Debt-Equity Decision-Making with and without Growth. Managerial Finance, 37, 765-787. https://doi.org/10.1108/03074351111146210

[26] Graham, J. (2000) How Big Are the Tax Benefits of Debt? Journal of Finance, 55, 
1901-1941. https://doi.org/10.1111/0022-1082.00277

[27] Korteweg, A. (2010) The Net Benefits of Leverage. Journal of Finance, 65, 2137 2170. https://doi.org/10.1111/j.1540-6261.2010.01612.x

[28] Van Binsbergen, J., Graham, J. and Yang, J. (2010) The Cost of Debt. Journal of Finance, 65, 2089-2136. https://doi.org/10.1111/j.1540-6261.2010.01611.x

[29] Hull, R. (2010) A Capital Structure Model with Growth. Investment Management and Financial Innovation, 7, 26-40.

[30] Tax Policy Center (2016). https://www.taxpolicycenter.org/model-estimates/distribution-business-income-au gust-2016/t16-0181-distribution-business-income

[31] National Federation of Independent Business (2013) Entity Choice and Effective Tax Rates.

http://www.s-corp.org/wp-content/uploads/2013/08/Quantria_Study_ETR_8-6-13_ Final_pm.pdf

[32] SBA, Office of Advocacy (2009) Effective Federal Income Tax Rates Faced by Small Businesses in the United States. Small Business Administration. https://www.sba.gov/sites/default/files/advocacy/rs343tot.pdf

[33] Tax Policy Center (2017). http://www.taxpolicycenter.org/taxvox/25-percent-rate-pass-through-businesses-he lps-rich-investors-not-small-businesses

[34] Damodaran, A. (2018). http://pages.stern.nyu.edu/ adamodar/

[35] Kisgen, D. (2006) Credit Ratings and Capital Structure. Journal of Finance, 61, 1035-1072. https://doi.org/10.1111/j.1540-6261.2006.00866.x

[36] U.S. Municipal Bonds (2018) Bloomberg Business. http://www.bloomberg.com/markets/rates-bonds/government-bonds/us

[37] Damodaran, A. (2014) Bond Ratings, Cost of Debt and Debt Ratios, Page 48. http://pages.stern.nyu.edu/ adamodar/pdfiles/cfovhds/cfpacket2.pdf

[38] Moody's Investor Services, Data Report, 25 September 2017. https://www.researchpool.com/download/?report_id=1537315\&show_pdf_data=true

[39] Bowman, W. (2015) The Price of NPO Debt, NPO Quarterly. https://nonprofitquarterly.org/2018/06/14/the-price-of-nonprofit-debt/

[40] Hull, R., Kwak, S. and Walker, R. (2018) Hedge Fund Variables and Short-Run SEO Returns. International Journal of Managerial Finance, 14, 322-341. https://doi.org/10.1108/IJMF-09-2017-0194

[41] U.S. Bureau of Economic Analysis (2018). http://www.multpl.com/us-real-gdp-growth-rate/table/by-year 


\section{Appendix A}

Proof of Equation (3): Gain to leverage $\left(G_{L}\right)$ for an unlevered pass-through with nongrowth, interest tax shield (ITS), and personal tax on retained earnings $(R E)$.

Since pass-through taxation is different, we modify the applicable $\mathrm{C}$ corp definitions from Section 3.1 used when presenting (1) to get the following passthrough definitions: $\alpha_{1}=\left(1-T_{E 1}\right) /\left(1-T_{D}\right) ; \alpha_{2}=\left(1-T_{E 2}\right) /\left(1-T_{E 1}\right)$; $G=r_{L}\left(G_{L}\right) /\left(1-T_{E 2}\right) ; E_{U}=\left(1-T_{E 1}\right) C / r_{U}$; and, $E_{L}=\left(1-T_{E 2}\right)(C-I) / r_{L}$. Given these definitions, we derive (3) as follows using the definition of $G_{L}=V_{L}-V_{U}$. Noting $V_{L}=E_{L}+D$ and $V_{U}$ is the same as $E_{U}$, we have: $G_{L}=E_{L}+D-E_{U}$. Inserting the definition for $E_{L}$ into this latter $G_{L}$ expression gives: $G_{L}=\frac{\left(1-T_{E 2}\right)(C-I)}{r_{L}}+D-E_{U}$. Multiplying out the first component and rearranging: $G_{L}=D-\frac{\left(1-T_{E 2}\right) I}{r_{L}}-E_{U}+\frac{\left(1-T_{E 2}\right) C}{r_{L}}$. Multiplying the second component by $\frac{\left(1-T_{D}\right) r_{D}}{\left(1-T_{D}\right) r_{D}}=1$ to get $-\left[\frac{\left(1-T_{E 2}\right) r_{D}}{\left(1-T_{D}\right) r_{L}}\right] \frac{\left(1-T_{D}\right) I}{r_{D}}$, which is $-\left[\frac{\left(1-T_{E 2}\right) r_{D}}{\left(1-T_{D}\right) r_{L}}\right] D$, factoring out $D$, and setting $\alpha_{1}=\frac{1-T_{E 2}}{1-T_{D}}$, we have: $G_{L}=\left[1-\frac{\alpha_{1} r_{D}}{r_{L}}\right] D-E_{U}+\frac{\left(1-T_{E 2}\right) C}{r_{L}}$. Multiplying the last component by $\frac{\left(1-T_{E 1}\right) r_{U}}{\left(1-T_{E 1}\right) r_{U}}=1$ to get $\left[\frac{\left(1-T_{E 2}\right) r_{U}}{\left(1-T_{E 1}\right) r_{L}}\right] \frac{\left(1-T_{E 1}\right) C}{r_{U}}$, which is $\left[\frac{\left(1-T_{E 2}\right) r_{U}}{\left(1-T_{E 1}\right) r_{L}}\right] E_{U}$, factoring out $E_{U}$ and setting $\alpha_{2}=\frac{1-T_{E 2}}{1-T_{E 1}}$, we have:

$$
G_{L_{P T-I T S}}^{D \rightarrow E}(\text { Nongrowth })=\left[1-\frac{\alpha_{1} r_{D}}{r_{L}}\right] D-\left[1-\frac{\alpha_{2} r_{U}}{r_{L}}\right] E_{U}
$$

where the $D \rightarrow E$ indicates a debt-for-equity transactions, $P T$ denotes a passthrough, and ITS indicates $I$ is tax-exempt. Q.E.D.

\section{Appendix B}

Proof of (4): Gain to leverage $\left(G_{L}\right)$ for an unlevered pass-through with growth, interest tax shield (ITS), and personal tax on retained earnings (RE).

Since pass-through taxation is different, we modify the applicable C corp definitions from Section 3.1 used when presenting (2) to get the following passthrough definitions: $\alpha_{1}=\left(1-T_{E 1}\right) /\left(1-T_{D}\right) ; \alpha_{2}=\left(1-T_{E 2}\right) /\left(1-T_{E 1}\right)$; $G=r_{L g}\left(G_{L}\right) /\left(1-T_{E 2}\right) ; \quad E_{U}=\left(1-T_{E 1}\right) C / r_{U g} ; \quad$ and, $E_{L}=\left(1-T_{E 2}\right)(C-I) / r_{L g}$. Given these definitions, we derive (4) as follows using the definition of $G_{L}=V_{L}-V_{U}$. Noting $V_{L}=E_{L}+D$ and $V_{U}$ is the same as $E_{U}$, we have: $G_{L}=E_{L}+D-E_{U}$. Inserting the definition for $E_{L}$ into this latter $G_{L}$ expression gives: $G_{L}=\frac{\left(1-T_{E 2}\right)(C-I)}{r_{L g}}+D-E_{U}$. Multiplying out the first component and 
rearranging: $G_{L}=D-\frac{\left(1-T_{E 2}\right) I}{r_{L g}}-E_{U}+\frac{\left(1-T_{E 2}\right) C}{r_{L g}}$. Multiplying the second component by $\frac{\left(1-T_{D}\right) r_{D}}{\left(1-T_{D}\right) r_{D}}=1$ to get $-\left[\frac{\left(1-T_{E 2}\right) r_{D}}{\left(1-T_{D}\right) r_{L g}}\right] \frac{\left(1-T_{D}\right) I}{r_{D}}$, which is $-\left[\frac{\left(1-T_{E 2}\right) r_{D}}{\left(1-T_{D}\right) r_{L g}}\right] D$, factoring out $D$, and setting $\alpha_{1}=\frac{1-T_{E 2}}{1-T_{D}}$, we have: $G_{L}=\left[1-\frac{\alpha_{1} r_{D}}{r_{L g}}\right] D-E_{U}+\frac{\left(1-T_{E 2}\right) C}{r_{L g}}$. Multiplying the last component by $\frac{\left(1-T_{E 1}\right) r_{U g}}{\left(1-T_{E 1}\right) r_{U g}}=1$ to get $\left[\frac{\left(1-T_{E 2}\right) r_{U g}}{\left(1-T_{E 1}\right) r_{L g}}\right] \frac{\left(1-T_{E 1}\right) C}{r_{U g}}$, which is $\left[\frac{\left(1-T_{E 2}\right) r_{U g}}{\left(1-T_{E 1}\right) r_{L g}}\right] E_{U}$, factoring out $E_{U}$, and setting $\alpha_{2}=\frac{1-T_{E 2}}{1-T_{E 1}}$, we have:

$$
G_{L_{P T-I T S}}^{D \rightarrow E}(\text { Growth })=\left[1-\frac{\alpha_{1} r_{D}}{r_{L g}}\right] D-\left[1-\frac{\alpha_{2} r_{U g}}{r_{L g}}\right] E_{U}
$$

Q.E.D.

\section{Appendix C}

Proof of (5): $G_{L}$ for an unlevered C corp with growth issuing debt to retire equity with a retained earnings tax shield (RTS) replacing an interest tax shield (ITS).

For a tax policy where $R T S$ replaces $I T S$, we modify the applicable C corp definitions from Section 3.1 used when presenting (2) to get the following definitions: $\alpha_{1}=\left(1-T_{E 2}\right) /\left(1-T_{D}\right)$ as $\left(1-T_{C 2}\right)$ falls out since $I$ is no longer deductible;

$$
D=\left(1-T_{D}\right)\left(1-T_{C 2}\right) I / r_{D}
$$

where $\left(1-T_{C 2}\right)$ indicates $I$ is now taxed at the corporate level;

$$
g_{U}=r_{U}(R E) / C
$$

where $\left(1-T_{C 1}\right)$ falls out of the numerator since there is no longer corporate taxation on $R E$;

$$
g_{L}=r_{L}(R E) /(C+G-I)
$$

where $\left(1-T_{C_{2}}\right.$ ) falls out of both the numerator (no tax on $R E$ ) and also the denominator ( $I$ is no longer deductible). Given these definitions, we derive (5) as follows using the definition of $G_{L}=V_{L}-V_{U}$. Noting $V_{L}=E_{L}+D$ and $V_{U}$ is the same as $E_{U}$, we have: $G_{L}=E_{L}+D-E_{U}$. Inserting

$E_{L}=\frac{\left(1-T_{E 2}\right)\left(1-T_{C 2}\right)(C-I)}{r_{L g}}$ into the latter $G_{L}$ expression gives:

$G_{L}=\frac{\left(1-T_{E 2}\right)\left(1-T_{C 2}\right)(C-I)}{r_{L g}}+D-E_{U}$. Multiplying out the first component and rearranging:

$G_{L}=D-\frac{\left(1-T_{E 2}\right)\left(1-T_{C 2}\right) I}{r_{L g}}-E_{U}+\frac{\left(1-T_{E 2}\right)\left(1-T_{C 2}\right) C}{r_{L g}}$. Multiplying the second 
component by $\frac{\left(1-T_{D}\right) r_{D}}{\left(1-T_{D}\right) r_{D}}=1$ to get $-\left[\frac{\left(1-T_{E 2}\right) r_{D}}{\left(1-T_{D}\right) r_{L g}}\right] \frac{\left(1-T_{D}\right)\left(1-T_{C 2}\right) I}{r_{D}}$, which is $-\left[\frac{\left(1-T_{E 2}\right) r_{D}}{\left(1-T_{D}\right) r_{L g}}\right] D$, factoring out $D$, and setting $\alpha_{1}=\frac{1-T_{E 2}}{1-T_{D}}$, we have: $G_{L}=\left[1-\frac{\alpha_{1} r_{D}}{r_{L g}}\right] D-E_{U}+\frac{\left(1-T_{E 2}\right)\left(1-T_{C 2}\right) C}{r_{L g}}$. Multiplying the last component by $\frac{\left(1-T_{E 1}\right)\left(1-T_{C 1}\right) r_{U g}}{\left(1-T_{E 1}\right)\left(1-T_{C 1}\right) r_{U g}}=1$, to get $\left(\frac{\left(1-T_{E 2}\right)\left(1-T_{C 2}\right)}{\left(1-T_{E 1}\right)\left(1-T_{C 1}\right)} \frac{r_{U g}}{r_{L g}}\right) \frac{\left(1-T_{E 1}\right)\left(1-T_{C 1}\right) C}{r_{U g}}$, which is $\left(\frac{\left(1-T_{E 2}\right)\left(1-T_{C 2}\right)}{\left(1-T_{E 1}\right)\left(1-T_{C 1}\right)} \frac{r_{U g}}{r_{L g}}\right) E_{U}$, factoring out $E_{U}$, and setting $\alpha_{2}=\frac{\left(1-T_{E 2}\right)\left(1-T_{C 2}\right)}{\left(1-T_{E 1}\right)\left(1-T_{C 1}\right)}$, we have:

$$
G_{L_{C \text { Corp }-R T S}^{D \rightarrow E}}^{D}(\text { Growth })=\left[1-\frac{\alpha_{1} r_{D}}{r_{L g}}\right] D-\left[1-\frac{\alpha_{2} r_{U g}}{r_{L g}}\right] E_{U}
$$

where $R T S$ indicates $R E$ is now tax-exempt instead of $I$ being tax exempt. Q.E.D.

\section{Appendix D}

Proof of (6): $G_{L}$ for an unlevered pass-through with growth issuing debt to retire equity with a retained earnings tax shield (RTS) replacing an interest tax shield (ITS).

For a tax policy where RTS replaces ITS, we modify the applicable pass-through definitions used when presenting (4) to get the following definitions: $\alpha_{1}=1 /\left(1-T_{D}\right)$ as $\left(1-T_{E 1}\right)$ falls out since $I$ is no longer deductible;

$$
D=\left(1-T_{D}\right)\left(1-T_{E 2}\right) I / r_{D}
$$

where $\left(1-T_{E 2}\right)$ indicates $I$ is now taxed at the pass-through level;

$$
g_{U}=r_{U}(R E) / C
$$

where $\left(1-T_{E 1}\right)$ falls out of the numerator since there is no longer taxation on $R E$; and,

$$
g_{L}=r_{L}(R E) /(C+G-I)
$$

where (1- $T_{E 2}$ ) falls out of numerator (no tax on $R E$ ) and denominator ( $I$ is no longer deductible). Given these definitions, we derive (6) as follows using the definition of $G_{L}=V_{L}-V_{U}$. Noting $V_{L}=E_{L}+D$ and $V_{U}$ is the same as $E_{U}$, we have: $G_{L}=E_{L}+D-E_{U}$. Inserting $E_{L}=\frac{\left(1-T_{E 2}\right)(C-I)}{r_{L g}}$ into the latter $G_{L}$ expression gives: $G_{L}=\frac{\left(1-T_{E 2}\right)(C-I)}{r_{L g}}+D-E_{U}$. Multiplying out the first component and rearranging: $G_{L}=D-\frac{\left(1-T_{E 2}\right) I}{r_{L g}}-E_{U}+\frac{\left(1-T_{E 2}\right) C}{r_{L g}}$. Multiplying the 
second component by $\frac{\left(1-T_{D}\right) r_{D}}{\left(1-T_{D}\right) r_{D}}=1$ to get $-\left[\frac{r_{D}}{\left(1-T_{D}\right) r_{L g}}\right] \frac{\left(1-T_{D}\right)\left(1-T_{E 2}\right) I}{r_{D}}$, which is $-\left[\frac{r_{D}}{\left(1-T_{D}\right) r_{L g}}\right] D$, factoring out $D$, and setting $\alpha_{1}=\frac{1}{1-T_{D}}$, we have: $G_{L}=\left[1-\frac{\alpha_{1} r_{D}}{r_{L g}}\right] D-E_{U}+\frac{\left(1-T_{E 2}\right) C}{r_{L g}}$. Multiplying the last component by $\frac{\left(1-T_{E 1}\right) r_{U g}}{\left(1-T_{E 1}\right) r_{U g}}=1$ to get $\left[\frac{\left(1-T_{E 2}\right) r_{U g}}{\left(1-T_{E 1}\right) r_{L g}}\right] \frac{\left(1-T_{E 1}\right) C}{r_{U g}}$, which is $\left[\frac{\left(1-T_{E 2}\right) r_{U g}}{\left(1-T_{E 1}\right) r_{L g}}\right] E_{U}$, factoring out $E_{U}$, and setting $\alpha_{2}=\frac{1-T_{E 2}}{1-T_{E 1}}$, we have:

$$
G_{L_{P T-R T S}}^{D \rightarrow E}(\text { Growth })=\left[1-\frac{\alpha_{1} r_{D}}{r_{L g}}\right] D-\left[1-\frac{\alpha_{2} r_{U g}}{r_{L g}}\right] E_{U}
$$

Q.E.D.

\section{Appendix E}

Proof of (7): $G_{L}$ for an unlevered C corp with growth issuing debt to retire equity with a partial interest tax shield (partial ITS) and/or a partial retained earnings tax shield (partial RTS).

For a tax policy restructuring that allows for a partial ITS and/or partial RTS where the tax rate is fractionally changed, we modify the $\mathrm{C}$ corp definitions for $I T S, R T S, \alpha_{1}, D, g_{U}$, and $g_{L}$ used when presenting (2) and (5) using two sets of multiplicand factors that all lie between 0 and 1 . First, $f_{1}$ is the fraction of a full $I T S$ where $f_{1}=1$ if a full ITS and $f_{1}=0$ if no ITS. Because some equations that are affected by ITS react in the opposite direction, it is necessary to have a factor that is the direct opposite to $f_{1}$. This factor is $f_{2}$ and equals $\left(1-f_{1}\right)$. Second, $p_{1}$ is the proportion of a full $R T S$ where $p_{1}=1$ is a full $R T S$ and $p_{1}=0$ if no RTS. Because some equations that are affected by $R T S$ react in the opposite direction, it is necessary to have a factor that is the opposite to $p_{1}$. This factor is $p_{2}$ and equals $p_{2}=\left(1-p_{1}\right)$. Using these factors, we get the following definitions: $\alpha_{1}=\left(1-T_{E 2}\right)\left(1-f_{1} T_{C 2}\right) /\left(1-T_{D}\right) ; D=\left(1-T_{D}\right)\left(1-f_{2} T_{C 2}\right) I / r_{D} ;$ $g_{U}=r_{U}\left(1-p_{2} T_{C 1}\right) R E / C ; g_{L}=r_{L}\left(1-p_{2} T_{C 2}\right) R E /\left[C+G-\left(1-f_{1} T_{C 2}\right) I\right]$; $E_{L}=\left(1-T_{E 2}\right)\left(1-T_{C 2}\right)(C-I) / r_{L g} ; I T S=f_{1} T_{C 2}(I)$; and, $R T S=p_{1} T_{C 2}(R E)$. Given these definitions, we know that Equation (7) is a hybrid of Equations (2) and (5) that have already been derived with the same expression but different definitions. To illustrate, we can see that the definition of $D=\left(1-T_{D}\right)\left(1-f_{2} T_{C 2}\right) I / r_{D}$ given for (7) lies between the definitions of $D$ given for Equations (2) and (5). For example, if $f_{2}=0$, then $D=\left(1-T_{D}\right) I / r_{D}$ which is the definition of $D$ given when deriving (2) and, if $f_{2}=1$, then $D=\left(1-T_{D}\right)\left(1-T_{C 2}\right) I / r_{D}$ which is the definition of $D$ given when deriving (5). Thus, it follows that (7) can be also expressed, in terms of its first two components, like other CSM growth equations but with different definitions and so we have: 


$$
G_{L_{C \text { Corp-Partial }}}^{D \rightarrow E}(\text { Growth })=\left[1-\frac{\alpha_{1} r_{D}}{r_{L g}}\right] D-\left[1-\frac{\alpha_{2} r_{U g}}{r_{L g}}\right] E_{U}
$$

where partial indicates a partial ITS and/or partial RTS is present. Q.E.D.

\section{Appendix F}

Proof of (8): $G_{L}$ for an unlevered pass-through with growth issuing debt to retire equity with a partial interest tax shield (partial ITS) and/or a partial retained earnings tax shield (partial RTS).

For a tax policy restructuring that allows for a partial ITS and/or partial RTS where the tax rate is fractionally changed, we modify the pass-through definitions for ITS, RTS, $\alpha_{1}, D, g_{U}$ and $g_{L}$ used when presenting (4) and (6) using two sets of multiplicand factors that all lie between 0 and 1. (See Appendix E for a description of these factors as they are the same.) Using these factors, we get the following definitions: $\alpha_{1}=\left(1-f_{1} T_{E 2}\right) /\left(1-T_{D}\right) ; D=\left(1-T_{D}\right)\left(1-f_{2} T_{E 2}\right) I / r_{D}$; $g_{U}=r_{U}\left(1-p_{2} T_{E 1}\right) R E / C ; g_{L}=r_{L}\left(1-p_{2} T_{E 2}\right) R E /\left[C+G-\left(1-f_{1} T_{E 2}\right) I\right]$; $E_{L}=\left(1-T_{E 2}\right)(C-I) / r_{L g} ; I T S=f_{1} T_{E 2}(I)$; and, $R T S=p_{1} T_{E 2}(R E)$. Given these definitions, we know that Equation (8) is a hybrid of Equations (4) and (6) that have already been derived with the same expression but different definitions. To illustrate, we can see that the definition of $D=\left(1-T_{D}\right)\left(1-f_{2} T_{E 2}\right) I / r_{D}$ given for (8) lies between the definitions of $D$ given in (4) and (6). For example, if $f_{2}=0$, then $D=\left(1-T_{D}\right) I / r_{D}$ which is the definition of $D$ when deriving for (4) and, if $f_{2}=1$, then $D=\left(1-T_{D}\right)\left(1-T_{E 2}\right) I / r_{D}$ which is the definition of $D$ when deriving for (6). Thus, it follows that (8) can be also expressed, in terms of its first two components, like other CSM growth equations and so we have:

$$
G_{L_{P T-\text { Partial }}^{D \rightarrow E}}(\text { Growth })=\left[1-\frac{\alpha_{1} r_{D}}{r_{L g}}\right] D-\left[1-\frac{\alpha_{2} r_{U g}}{r_{L g}}\right] E_{U} .
$$

